\title{
Localized pulmonary Wegener's granuloma simulating lung cancer: report of four cases
}

\author{
J.B. B LEN NERHASSETT, J. BORR IE, I L ICHTER \\ and A. J. TA Y L O R \\ Departments of Pathology, Thoracic Surgery, and Respiratory Medicine, \\ University of Otago, Dunedin, New Zealand
}

\begin{abstract}
Blennerhassett, J. B., Borrie, J., Lichter, I., and Taylor, A. J. (1976). Thorax, 31, 576-584. Localized pulmonary Wegener's granuloma simulating lung cancer: report of four cases. Clinical features suggesting lung disease in three patients and a chance chest radiograph in the fourth led to films showing localized lung lesions with some characteristics of neoplasms. Two were heavy smokers, two were non-smokers. In two the lesion was peripheral, in one lobar (RUL), and in the fourth it crossed the interlobar fissure (apical and posterior segments LUL and apical LLL). Malignant cells were not seen on sputum cytology examination in any, but in one, atypical cells were reported. All four patients had lung resection for suspected cancer, two by pneumonectomy, one by lobectomy, and one lingulectomy. All patients recovered, and their clinical course has so far been uniformly benign. Two have been followed long term (16 and 10 years), one $2 \frac{1}{2}$ years, and one a year. Pathologically, the lesions appeared to be strictly limited without extrapulmonary involvement, except that the patient followed for one year has developed hyporegenerative anaemia responsive to prednisone therapy. The pathological features of focal necrosis, granulomatous inflammation, and vasculitis were sufficiently striking, although often focal, to suggest that incisional biopsy from frozen-section histological diagnosis could be useful to prevent extensive lung resection for lesions not positively diagnosed before thoracotomy.
\end{abstract}

Wegener's granulomatosis was originally described by Klinger in 1931 and described in detail by Wegener $(1936 ; 1939)$. It is now generally considered (Fahey et al., 1954) as a disorder characterized by granulomas in the nasopharynx or antra, lesions in the respiratory tract, a generalized vasculitis, and a focal glomerulonephritis of varying severity. The progress of this disease, once established, is usually rapid, and death is the usual outcome, often within a few weeks. The most common cause of death is renal failure, which was present in $83 \%$ of Walton's (1958) series. The disease appears to bear a relationship to Löffler's syndrome, allergic granulomatosis (Churg and Strauss, 1951), and polyarteritis (Crofton et al., 1952).

Carrington and Liebow (1966) described apparently localized forms of vasculitis and granulomatosis, with some of the features seen in the classical Wegener's syndrome but other features absent, in 10 women and six men. Presenting symptoms included cough, chest pain, dyspnoeă sore throat, painful subcutaneous nodules, pyrexis and weight loss. The chest radiograph was abno mal in all cases with usually multiple rounded of nodular opacities up to $5 \mathrm{~cm}$ in diameter, more common in the lower lung fields. Larger opacities were commonly cavitated. There was no evidenct of renal involvement. Grossly and microscopically; the lung lesions were similar to, but more limited than those seen in the generalized form of the syndrome. Chronic inflammatory cells and mult nucleated giant cells were seen around necrotfe tissue, and typical epithelioid cell granulomas were present in some of the larger lesions. Angiitis w widespread at the periphery of the lesions an resembled the changes found in the lung vessels in the previously described Wegener's syndromes Nodular and ulcerating lesions present in the upper respiratory tract and in the skin were attro? buted to vasculitis while muscle biopsy sometime showed evidence of acute arteritis. The absence 
of acute glomerulonephritis and of nasopharyngeal granuloma was notable pathologically as well as clinically. Five patients died within a year from generalized vasculitis and/or from the lung involvement itself. Two died from unrelated diseases and nine patients survived for longer than a year; seven were treated with corticosteroids.

Liebow, Carrington, and Friedman (1972) subsequently delineated another variant of the limited form of Wegener's granulomatosis and named it 'lymphomatoid granulomatosis'.

This paper describes four patients in whom lung lesions, diagnosed preoperatively as carcinoma, were found to be due to localized Wegener's granuloma, and attempts to assess whether needle biopsy or frozen section at operation could provide the correct diagnosis.

\section{CLINICAL REPORTS}

CASE 1 A 50-year-old Latvian woman was referred to the Chest Clinic, Dunedin Hospital for the first time on 8 December 1971. Six years previously at another hospital an opacity had been found in the left lung field and at thoracotomy in June 1965 a solid focus was removed from the posterior basal segment of the left lung. The pathological report was of a caseating granuloma with a few scattered satellite lesions around the periphery. The Ziehl Neelsen stain for tubercle bacilli was said to be positive, and pulmonary tuberculosis was diagnosed.

She was treated with various combinations of antituberculosis chemotherapy for a total of 24 months. However, follow-up in April 1971 (4 years later) showed bilateral basal radiographic opacities. Tomography showed an area of collapse in the left lung base with a more solid opacity in this region while on the right side were three small rounded intrapulmonary lesions. There was no evidence of calcification or cavitation. All sputum tests proved negative for acid-fast bacilli on both direct smear and culture; however, antituberculosis chemotherapy was reinstituted, and the radiographic changes were partially resolved. In November of that year she came to Dunedin. Through 1972 she continued on isoniazid and cycloserine in doses of $300 \mathrm{mg}$ and $500 \mathrm{mg}$ daily respectively.

In February 1973 she complained of pain over the left lower chest, and there was increased radiographic shadowing at the base of the left lung (Fig. 1). Physical examination revealed only impaired percussion note and harsh breath sounds at the base of the left lung. Blood screen and serum electrolyte determinations revealed no abnormality. Direct smear sputum examination proved negative for tubercle bacilli. An electrocardiogram was normal. Sputum cytology showed atypical cells but no neoplastic cells. The vital capacity was $31, \mathrm{FEV}_{1} 1.741$, FVC 2.981 , and $\mathrm{FEV}_{1} / \mathrm{VC} 58 \%$ (predicted VC 3.22, $\mathrm{FEV}_{1}$ 2.51, $\mathrm{FEV}_{1} / \mathrm{VC} 78 \%$ ). Later chest films suggested cavitation in the left lower lobe.

Because of the strong suspicion of lung cancer in this 15 cigarettes per day smoker, thoracotomy was undertaken on 29 March 1973 and the left lower lobe with its contained 'tumour' was excised.

CASE 2 A 64-year-old Irish clerk was referred on 18 July 1973 complaining of a heavy nose-bleed in April followed by a severe cold, morning wheeze, and cough productive of discoloured sputum. There had been a $13 \mathrm{~kg}$ weight loss, night sweats, weakness, and anorexia. He had not smoked for 40 years. He was pale, thin, and apprehensive. Movement over the left upper chest was reduced with vesicular breathing and no added sounds. No other abnormal physical findings were demonstrated; blood screen and serum electrolyte levels were normal. The chest radiograph showed shadowing medially in the apical segment of the left upper lobe (Fig. 2). Atypical cells were reported on sputum cytology. Bronchoscopy was normal; no malignant cells were seen in the bronchial aspirate. Mediastinoscopy revealed only normal lymphoid tissue on the left side of the trachea.

As the abnormal radiograph and symptoms persisted, a provisional diagnosis of neoplasm in the apical segment of the left upper lobe was made, and thoracotomy was undertaken on 7 August 1973. A mass was found in the apical and posterior segments of the left upper lobe. As this reached the hilum between the upper and lower lobes, left pneumonectomy was carried out in the belief that it was a carcinoma (Fig. 3).

The patient was discharged on 23 August 1973 and continued well when last seen in November 1974.

CASE 3 A 68-year-old woman was admitted for investigation on 5 January 1975 after a routine chest film had revealed an ill-defined opacity in the left upper zone. It was clearest in the $14 \mathrm{~cm}$ tomographic cut (Fig. 4). All clinical investigations were normal apart from an ESR of $48 \mathrm{~mm}$ per hour Westergren. The liver and spleen, outlined by nuclear scanning, were normal. She was a non-smoker. Over the past four years her weight 


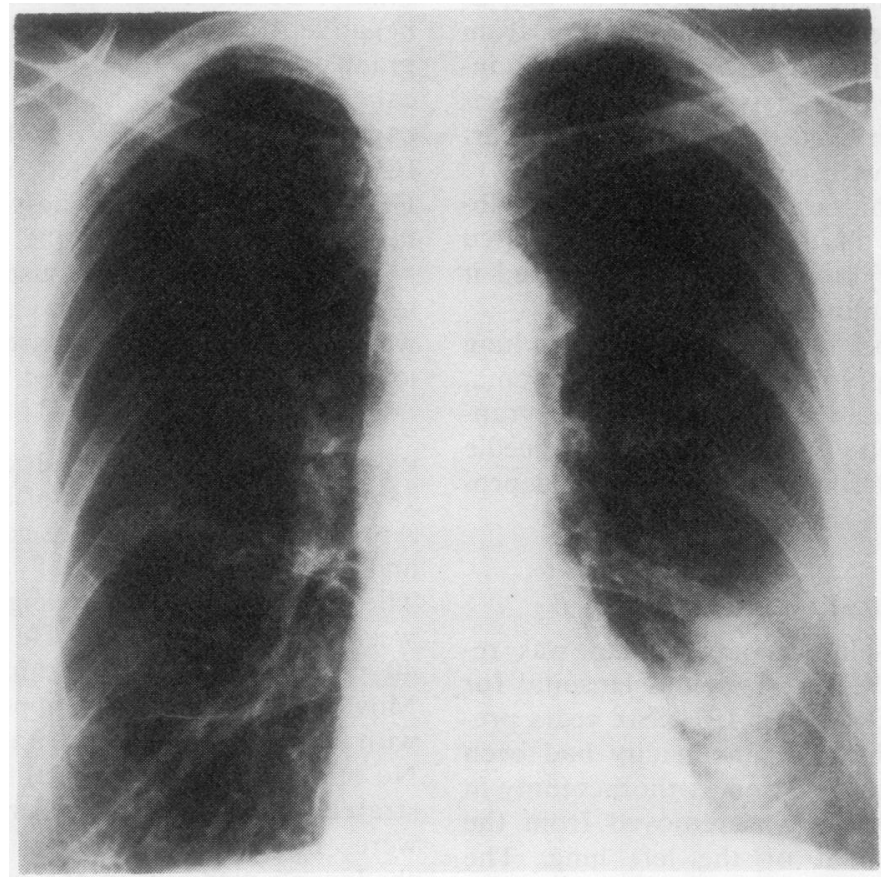

(a)

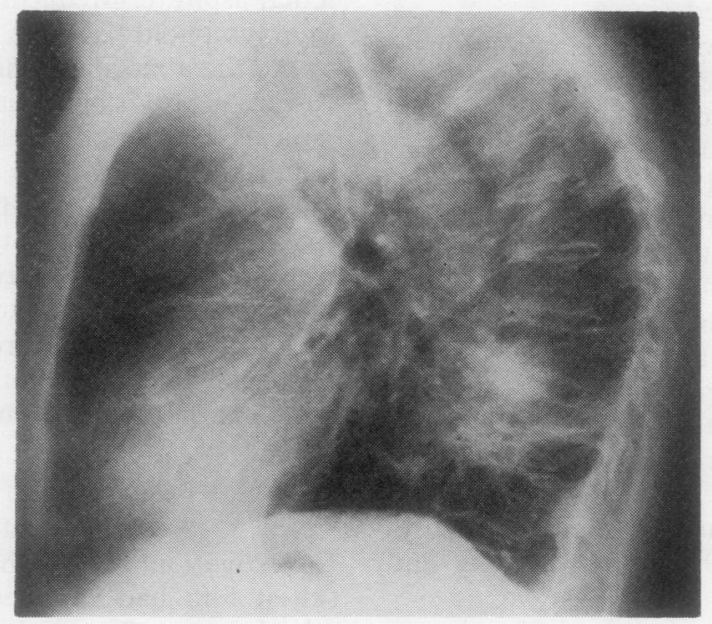

(b)

FIG. 1 ( $a$ and b) Case 1. Postero-anterior and lateral chest films showing left basal shadowing. 


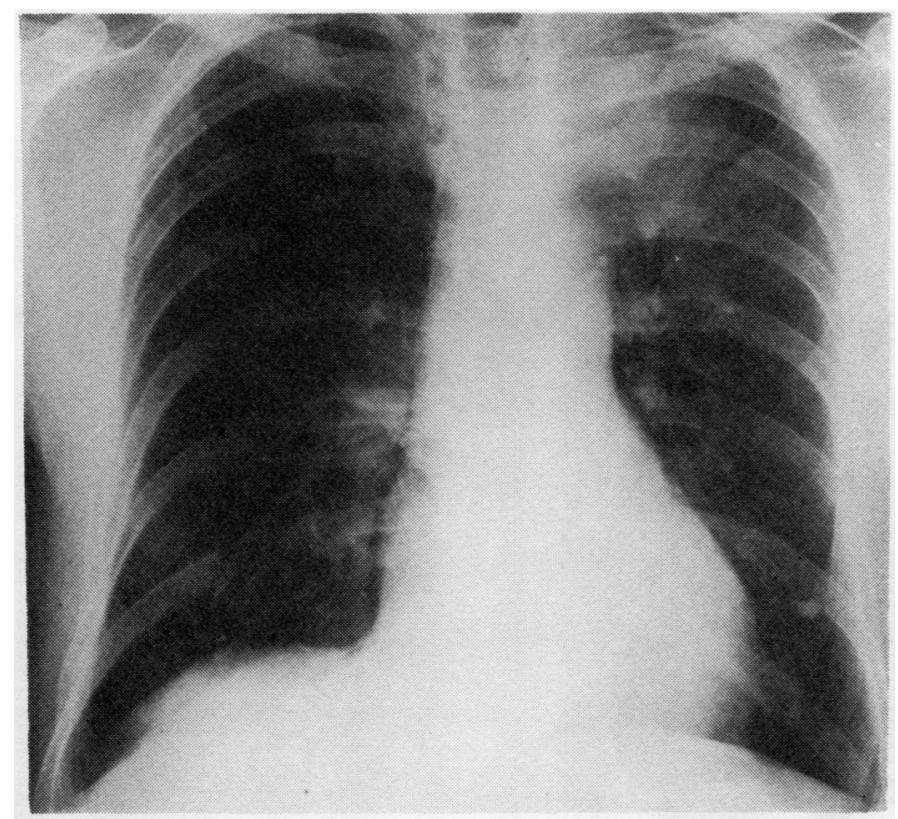

FIG. 2. Case 2. Postero-anterior chest film showing opacification of the medial side of the left upper lobe.

had fallen from $75 \mathrm{~kg}$ to $61 \mathrm{~kg}$. Bronchoscopy revealed no abnormality.

Because of a provisional diagnosis of peripheral bronchial neoplasm, lobectomy was performed on 16 January 1975. Through a left posterolateral thoracotomy a small, apparently localized mass was found in the lingular segment which was resected. There was no nodal involvement. The patient made a satisfactory recovery from the operation and was discharged 12 days postoperatively.

She was readmitted six months later with enlarged right supraclavicular lymph nodes and anaemia (haemoglobin $7 \cdot 7 \mathrm{~g} / \mathrm{dl}$ ) which was found to be of the hyporegenerative type. The ESR was $138 \mathrm{~mm}$ per hour (Westergren). Kidney function was normal; examination of other systems showed no abnormality.

The cervical lymph nodes were excised and showed sinus histiocytic hyperplasia with giantcell reaction. The lymph node hyperplasia and the anaemia were considered to be manifestations of Wegener's syndrome, and the patient was placed on prednisone and cyclophosphamide. Within 14 days the ESR fell to $15 \mathrm{~mm}$ per hour and the haemoglobin levels showed progressive improvement, but lymphadenopathy has persisted (January 1976).

CASE 4 A 64-year-old man was admitted on 10 February 1953 suffering from attacks of breathlessness on effort, weakness, and a $13 \mathrm{~kg}$ weight loss in one month. He had increasing pain in the right chest and whitish sputum with no blood staining. He had been perfectly well until the year before, and able to work in a brewery and to lift heavy crates of bottles. Three months before admission he had had right-sided pneumonia with fever and cough. He smoked $150 \mathrm{~g}$ of cigarette tobacco per week. Physical examination revealed reduced movement of the upper right chest with dullness to percussion and bronchial breathing. Chest films showed pathological changes present in the right lung field provisionally ascribed to partial collapse associated with a carcinoma involving the right upper lobe bronchus. Tomography showed the lesion in the lower portion of the axillary segment of the right lung to be solid and the rest of the upper lobe honey-combed by cavities. The right hilar lymph nodes were enlarged. At bronchoscopy the only abnormality seen was a distorted, difficult to inspect right 


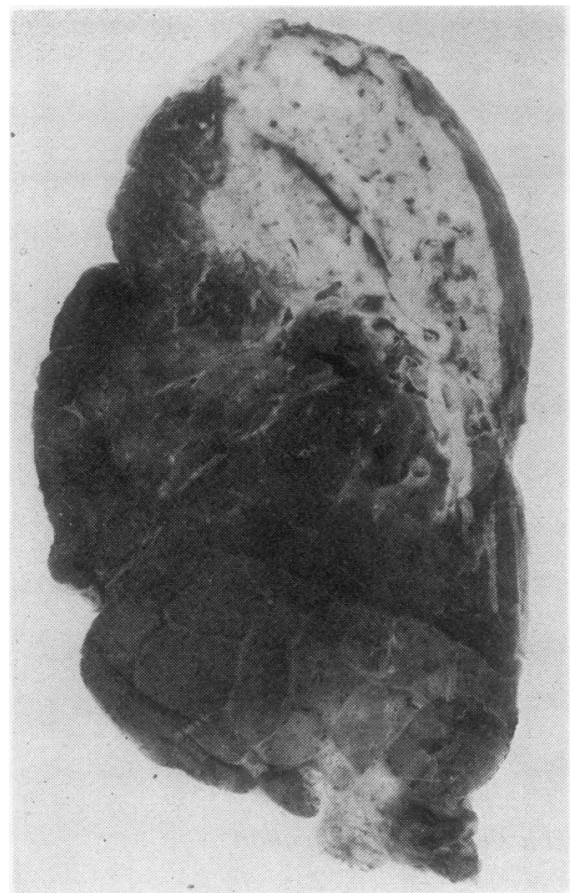

FIG. 3. Case 2. The sliced left lung shows a lesion in the left upper lobe.

upper lobe orifice. Mucosal biopsies showed normal bronchial mucosa.

In view of the extent of the radiographic changes and the likelihood of this being a primary lung cancer, thoracotomy was performed one month after admission. The upper lobe was deeply adherent to the parietal chest wall and contained a 'large mass'. The adhesions surrounding the upper lobe were divided, and thereafter right pneumonectomy was performed. The patient made an uninterrupted recovery. The nature of this granuloma had never been clarified. After discovery of cases 1-3 of this report, re-checking by one of us led to a re-assessment of this lesion as localized Wegener's granuloma.

He continued well until he was admitted to Dunedin Hospital again on 26 June 1968 for treatment of heart block by artificial cardiac pacing. He died in December 1969 in an old people's home aged 80 years.

\section{PATHOLOGY}

The pathological appearance of all four resected specimens was similar.

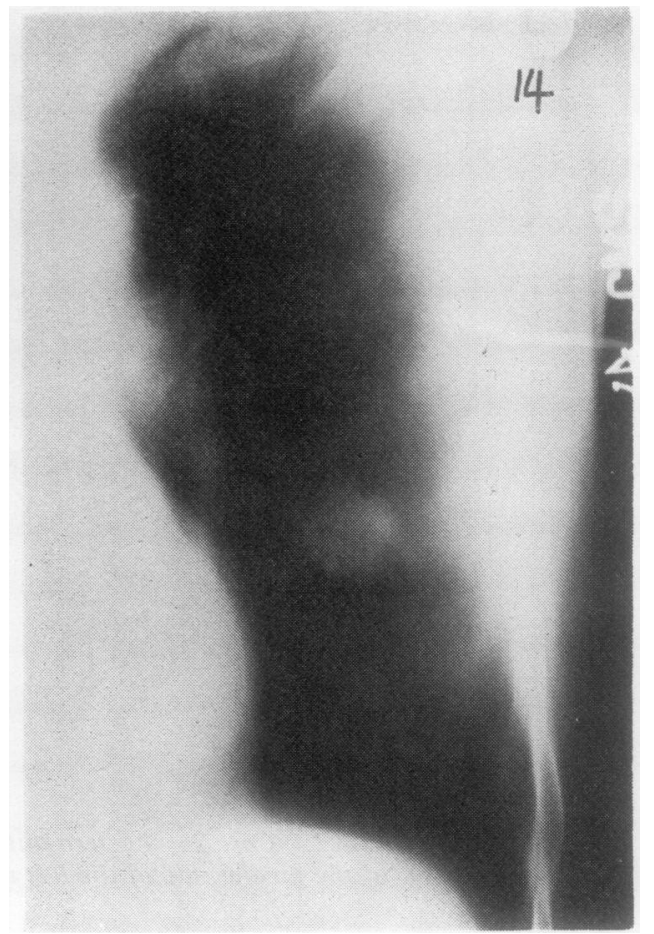

FIG. 4. Case 3. Tomogram of left lung showing the solitary round lesion.

CASE 1 The specimen of left lower lobe showed extensive fibrous tags over the pleural surface, and $\mathrm{O}$ a portion of parietal pleura was adherent laterally. $\tilde{x}$ Palpable deep within the lung substance were several firm masses. Multiple lung sections showed that the largest mass involved the pleura and 0 measured a maximum of $6 \mathrm{~cm}$ in diameter. Its cut surface was firm with rubbery hard areas and had응 an irregular yellowish-white appearance flecked $\supset$ with anthracotic pigment. Multiple smaller similar을. masses, down to $0.4 \mathrm{~cm}$ diameter, were scattered $\bar{N}$ through the lung adjacent to the main mass. Thereappeared to be a central small area of necrosis in $N$ the largest mass but no frank cavitation. The edge $\underset{\omega}{N}$ of each mass was irregular and shaded off into the surrounding lung. No remnant lung markingse could be identified in these lesions which appeared $\overparen{D}$ to have destroyed the outline of the normal lung? parenchyma. No major bronchial communication 7 was evident in any of the masses; lymph nodes $\frac{\vec{P}}{0}$ were normal.

Microscopically there were three major $\frac{\mathbb{Q}}{\mathbb{Q}}$ features. First, the main part of the masses com- 
prised irregularly arranged fibrous tissue in which there were zones of necrosis and extensive infiltration by lymphocytes and plasma cells (Fig. 5). Second was the presence of large numbers of multinucleated giant cells, many of which were of Langhans type (Fig. 6A). The third and most striking feature was the presence of a florid vasculitis of two types. In some areas a prominent feature was vasculitis comprising predominantly lymphocytes dissecting the intima of many small pulmonary arteries (Fig. 6B); in other areas, larger pulmonary artery walls appeared completely destroyed by a frankly giant-cell granulomatous vasculitis with complete occlusion of the vessel concerned (Fig. 7). It was not possible clearly to relate the occluded vessels to the zones of necrosis within the involved areas of lung, but in many sections the vessel involved was immediately adjacent to such a zone of necrosis. The areas of affected lung appeared to be reasonably localized although vascular involvement could be seen at the edges of the lesions. The intervening lung tissue appeared completely normal.

A review of the specimen resected eight years previously showed identical changes although in a smaller area of lung.

CASE 2 The resected left lung showed an upper lobe mass approximately $10 \mathrm{~cm}$ in diameter and with an identical gross appearance to that of case 1 (Fig. 3). Microscopically identical changes were seen, the only addition being the presence of giant cells but not vasculitis in several enlarged hilar lymph nodes.

CASE 3 The resected lingula showed a similar 2 $\mathrm{cm}$ diameter nodule with irregular edges. Microscopically identical features were seen, including the presence of a frankly granulomatous vasculitis, but without extensive necrosis. Panvascular and peribronchial infiltration with lymphocytes

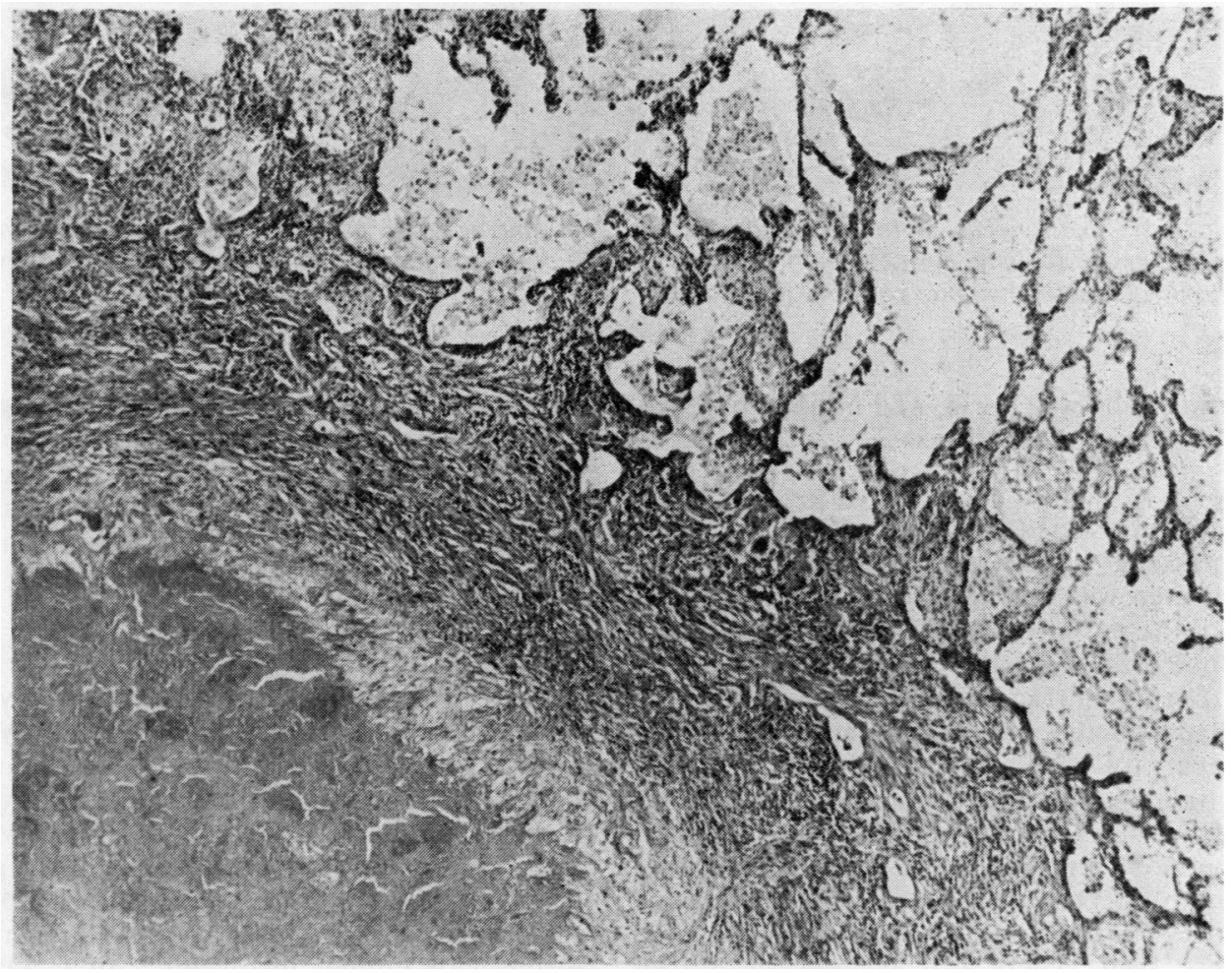

FIG. 5. A zone of necrosis (lower left) is surrounded by granulamatous inflammation with fibrosis. More normal alveoli are in the right upper field. 


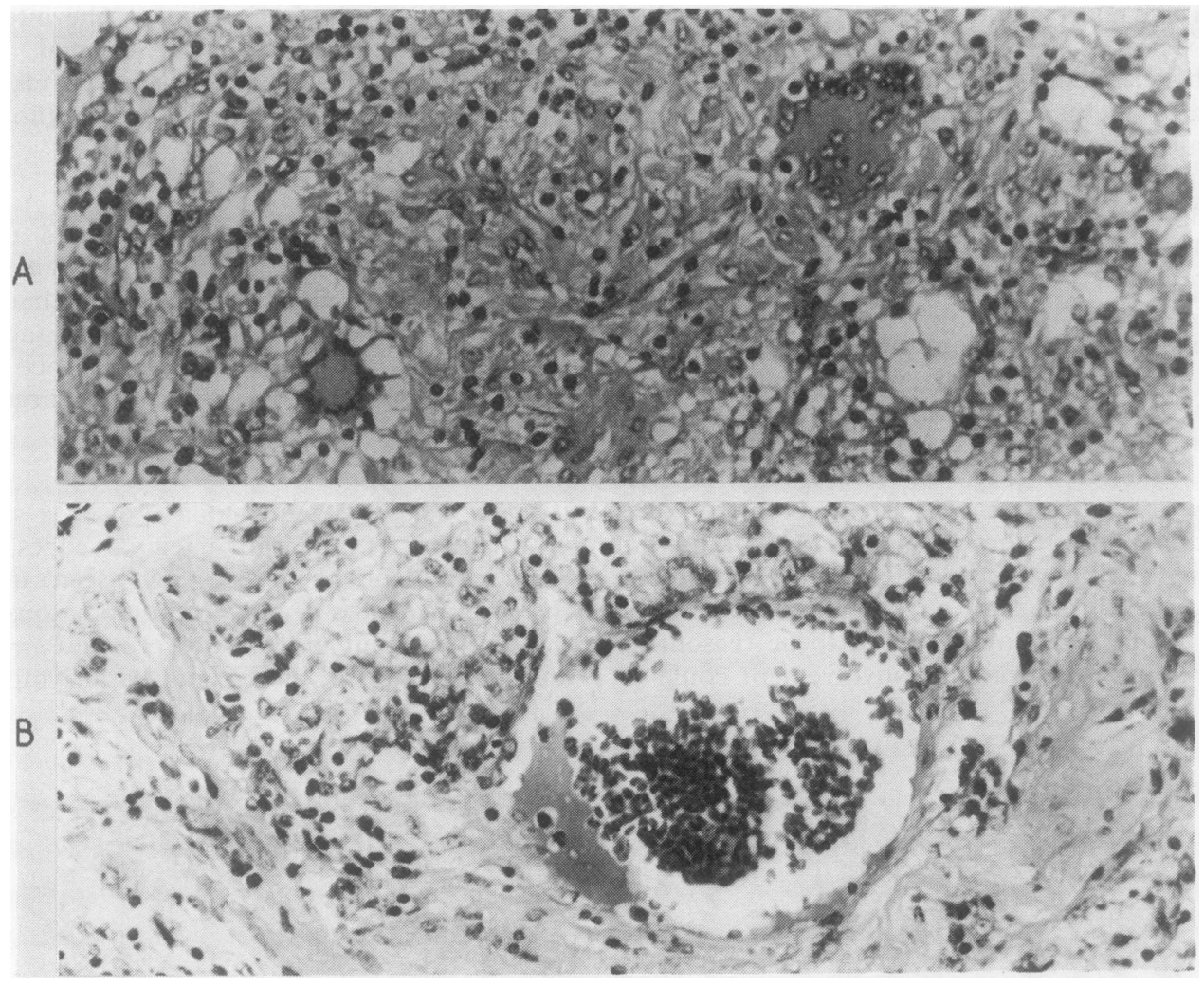

FIG. 6 (A) Typical multinucleated giant cells in the area of granulomatous inflammation (Haematoxylin and eosin $\times 280$ ). (B) The intima of a small pulmonary artery is extensively infiltrated with lymphocytes and plasma cells $(H$ and $E \times 280)$.

and plasma cells was florid, and eosinophil leucocytes were prominent in areas.

CASE 4 The resected material was reviewed and re-examined 20 years after the pneumonectomy. The specimen was described as showing disorganization of the posterior and apical segments of the upper lobe with densely adherent pleura in this region. The cut surface revealed extensive fibrosis and collapse in the posterior segment and in the central part of the apical segment widespread patchy yellowish consolidation. Histological restudy of the blocks from the posterior segment of the upper lobe showed severe disorganization of the lung architecture by an extensive granulomatous process in which many multinucleated giant cells were seen. There was widespread fibrosis associated with the chronic inflammatory process and considerable collapse with alveolar fibrosis.
Only small areas of necrosis were seen. Again, the most striking change was the presence of a puli monary vasculitis characterized by chronic inflam matory cells, predominantly lymphocytes, disseco ting the intima (Fig. 6B). There was no frank giant-cell vasculitis or fibrinoid necrosis.

\section{DISCUSSION}

Lung lesions in these four cases showed vascular granulomatous, and necrotizing lesions typical of those seen in Wegener's granulomatosis and iden tical with those described in the limited form of the syndrome by Carrington and Liebow (1966) The vascular lesions varied from a florid granulomatous vasculitis with extensive destruction of the wall and giant-cell infiltration to rather milde? forms with intimal involvement only. Often the presence of vasculitis of the latter type became clear only by examination of multiple sections 


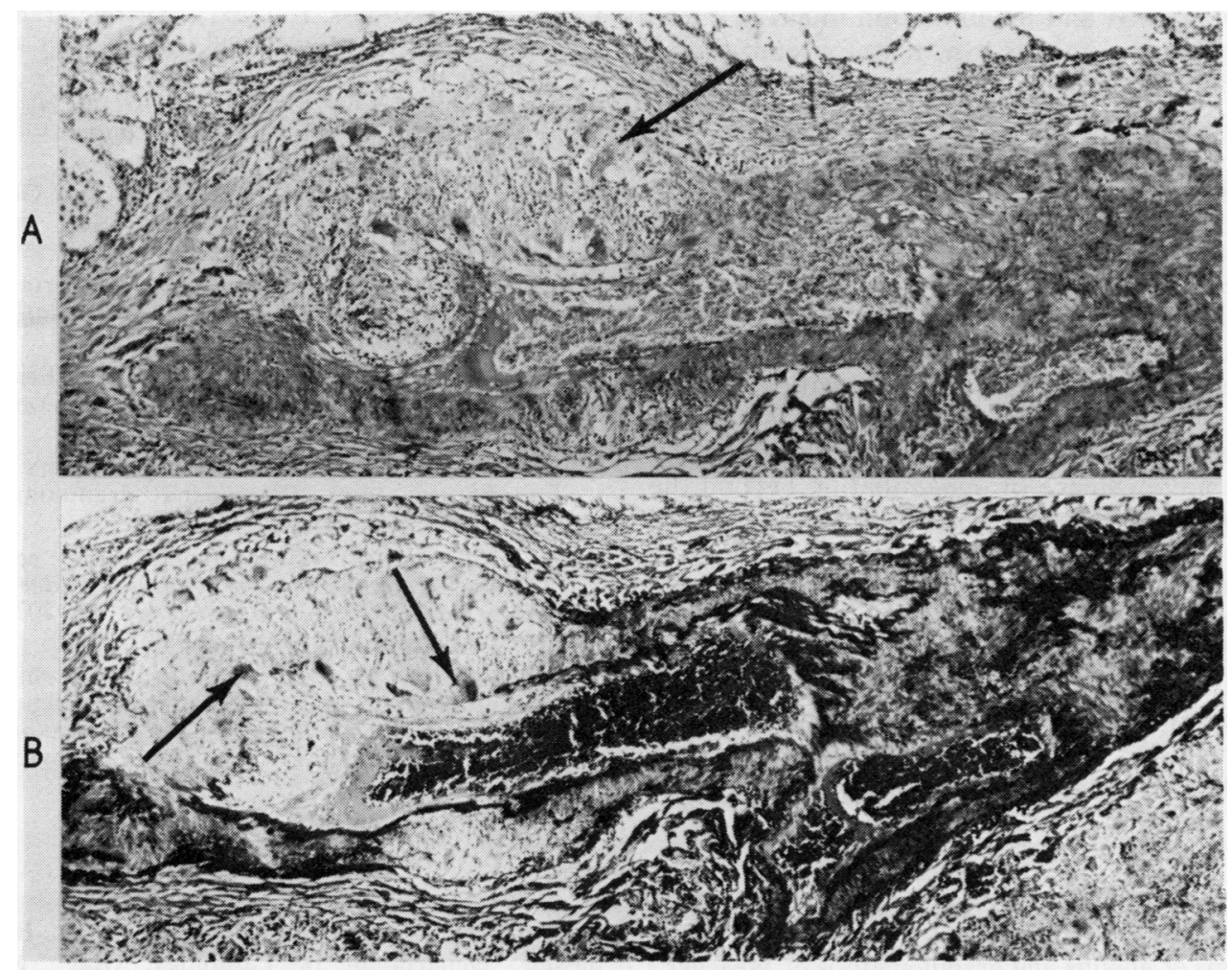

FIG. 7 (A) A medium-sized pulmonary artery is completely occluded and its wall replaced by giant-cell granulomatous inflammation (arrow) $(H$ and $E \times 45)$. $(B)$ Corresponding area of the same artery with internal and external elastic laminae stained black. Granulomatous infiltration completely destroys the media. Giant cells are prominent (arrows) (elastic van Gieson $\times 45$ ).

stained to display elastic tissue. Necrotizing and granulomatous involvement of the parenchyma was conspicuous in these cases but no frank cavitation was seen. Instead, a prominent feature between the granulomatous and necrotizing areas was pulmonary fibrosis with chronic inflammatory cell infiltration, and in this disorder examination of many blocks of tissue may be required for exact diagnosis.

The lesions in these four cases appeared to be strictly limited without evidence of involvement outside the respiratory tract except for the presence of a rather florid sinus histiocytosis (with giant cells in one case) in lymph nodes draining the affected lung. In particular, there was no evidence of renal involvement and none of the patients has thus far developed skin or nasal lesions, although one patient (case 3) has now (December 1975) hyporegenerative anaemia responsive to prednisone therapy and particularly florid reactive lymphoid hyperplasia in cervical nodes.

The striking clinical presentation has been one mimicking the gradual extension of a malignant process. In three of these four cases, the disease has been, in contrast to the usual multiple lung shadow presentation, confined to one side, and in three cases to one location on this side closely resembling bronchial carcinoma. The extensive fibrosis and relatively ill-defined margins of the lesion found at thoracotomy also suggested an infiltrating malignancy.

The pathological lesions were sufficiently striking to suggest that incisional biopsy and frozensection histological diagnosis would be useful to prevent extensive removal of lung for a condition which is not an epithelial malignancy. While typical zones of granulomatous vasculitis should be readily recognizable and establish the diagnosis during operation, examination of more nonspecific 
zones of fibrosis and inflammation might still lead to inconclusive results. In these circumstances where doubt exists, examination of multiple blocks from incisional biopsy by frozen section should help to exclude malignancy even where a definitive diagnosis is not possible by frozen-section technique alone. This course is recommended in situations where carcinoma is suspected but has not been absolutely confirmed by biopsy or sputum cytology.

The clinical course of these four patients so far has been uniformly benign. In two patients (cases 1 and 4) there has been more than 10 years' follow-up since the original histological diagnosis without any evidence of dissemination beyond the lung. In the other two patients (cases 2 and 3 ), while follow-up has been shorter and there have been some constitutional symptoms and vague chest pain following tissue diagnosis, there has again been no evidence of extrapulmonary dissemination. In neither of the patients with longterm follow-up was steroid or immunosuppressive therapy given, but in one (case 3), a short course of such therapy has restored a high ESR to normal levels.

\section{REFERENCES}

Carrington, C. B. and Liebow, A. A. (1966). Limited forms of angiitis and granulomatosis of Wegener's type. American Journal of Medicine, 41, 497.

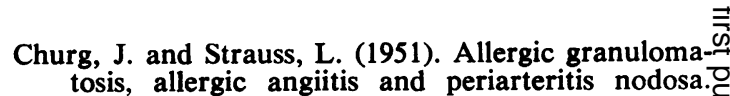
A merican Journal of Pathology, 27, 277.

Crofton, J. W., Livingstone, J. L., Oswald, N. C., and $\frac{\overline{\bar{c}}}{\overline{\mathrm{d}}}$ Roberts, A. T. M. (1952). Pulmonary eosino-市 philia. Thorax, 7, 1.

Fahey, J. L., Leonard, E., Churg, J., and Godman, G. (1954). Wegener's granulomatosis. American $\vec{\circ}$ Journal of Medicine, 17, 168.

Klinger, H. (1931). Grenzformen der Periarteriitis $\vec{\omega}$ nodosa. Frankfurter Zeitschrift für Pathologie, 42, 455. Cited by Fahey et al. (1954).

Liebow, A. A., Carrington, C. R., and Friedman, $\omega$ P. J. (1972). Lymphomatoid granulomatosis. $\vec{\circ}$ Human Pathology, 3, 457.

Walton, E. W. (1958). Giant-cell granuloma of the respiratory tract (Wegener's granulomatosis).o British Medical Journal, 2, 265.

Wegener, F. (1936). Über generalisierte septische $\overrightarrow{0}$ Gefässerkrankungen. Verhandlungen der Deut-n schen pathologischen Gesellschaft, 29, 202. Citedo by Carrington and Liebow (1966).

Wegener, F. (1939). UUber eine eigenartige rhinogeneGranulomatose mit besonderer Beteiligung des Arteriensystems. Beiträge zur pathologischenos Anatomie, 102, 36. Cited by Carrington and Liebow (1966).

Requests for reprints to: Professor J. B. Blenner hassett, Department of Pathology, Otago Medica School, P.O. Box 913, Dunedin, New Zealand. 